\title{
MULTIPRODUCT MULTINATIONALS
}

AND RECIPROCAL FDI DUMPING

Richard E. Baldwin

Gianmarco I. P. Ottaviano

Working Paper 6483 


\section{MULTIPRODUCT MULTINATIONALS AND RECIPROCAL FDI DUMPING}

Richard E. Baldwin

Gianmarco I. P. Ottaviano

Working Paper 6483

http://www.nber.org/papers/w6483

\section{NATIONAL BUREAU OF ECONOMIC RESEARCH 1050 Massachusetts Avenue \\ Cambridge, MA 02138 \\ March 1998}

We wish to thank Philippe Martin, Tony Venables and participants at Bocconi and CORE seminars for comments and discussion. Financial support came from Swiss NSF grant 1214-043580.95. Any opinions expressed are those of the authors and not those of the National Bureau of Economic Research.

(C) 1998 by Richard E. Baldwin and Gianmarco I. P. Ottaviano. All rights reserved. Short sections of text, not to exceed two paragraphs, may be quoted without explicit permission provided that full credit, including (C) notice, is given to the source. 
Multiproduct Multinationals and Reciprocal FDI Dumping

Richard E. Baldwin and Gianmarco I. P. Ottaviano

NBER Working Paper No. 6483

March 1998

JEL Nos. F23, F12

$\underline{\text { ABSTRACT }}$

The global pattern of foreign direct investment (FDI) is quite similar to the world trade pattern. In particular, intraindustry FDI between rich nations is almost as pervasive as intraindustry trade among rich nations. In the "standard" MNC model (of Markusen, Venables, Brainard, and others), FDI is driven by a tradeoff between proximity and scale, so firms typically supply the foreign market via exports or via FDI. The close correlation of two-way trade and investment flows is therefore difficult to explain with the standard model.

We propose a model of multiproduct MNCs where firms simultaneously engage in intraindustry FDI and intraindustry trade.

Richard E. Baldwin

Graduate Institute of International Studies University of Geneva

11 a, Avenue de la Paix

CH-1202 Geneva

SWITZERLAND

and NBER

Baldwin@hei.unige.ch
Gianmarco I. P. Ottaviano

Dip. di Scienze Economiche University of Bologna

Piazza Scaravilli, 2

40126 Bologna

ITALY 


\section{Introduction}

One of the most striking aspects of foreign direct investment (FDI) is the similarity between the world trade pattern and the world direct investment pattern. For instance, when it comes to goods trade, the advanced industrialised nations are both the biggest exporters and their own best customers. The same is true of foreign direct investment; According to Hummels and Stern (1994), the rich nations account for $97 \%$ of direct investment outflows and $75 \%$ of the inflows. The similarity also extends to the composition of trade and investment. For instance, intraindustry trade among rich nations accounts for the bulk of world trade. Similarly, there is great deal of two-way foreign direct investment among rich nations, even at the industry level. The Markusen (1995) survey of multinationals, for instance, includes the importance of intraindustry FDI as one of six stylized facts.

Moreover, the industries in which we see a lot of intraindustry trade among similar nations are also typically the industries in which there is a great deal of intraindustry FDI, according to Rugman (1985). Anecdotal evidence can be found in sectors such as transport equipment, chemicals, pharmaceutical, and processed foods. Finally, econometric evidence presented in Blomström, Lipsey and Kulchycky (1988) suggest that trade is not a substitute for investment, even at the firm level.

This importance of intraindustry FDI is a puzzle for the classic Hymer (1976) "advantages" approach to multinationals, which asserts that multinationals must have some sort of advantage over local firms. After all, if French pharmaceutical firms have an advantage over German drug companies in Germany, how can German pharmaceutical firms have an advantage in France?

The earliest 'new trade' models of multinational corporations (MNC) - e.g. Markusen (1984), Helpman (1984) and Horstmann and Markusen (1987), Smith (1987), and Motta (1992) - did not focus on explaining intraindustry FDI. More recently, however, a series of papers have extended the early models in a way that does account for two-way FDI. Horstmann and Markusen (1992) sets out the basic paradigm which has been pursued by Brainard (1993), Markusen and Venables (1995), and others. The key elements of this approach are firm-level scale economies, plant-level scale economies and trade costs. These so-called tariff-jumping models of FDI are driven by a tradeoff between proximity and 
scale. Namely, firms can supply the foreign market via exports or via FDI. Given plantlevel scale economies, exporting would always be the lowest cost option were it not for trade costs. However, when trade costs are high enough and the countries similar enough in size, it is cheaper to supply both markets from local plants instead of via trade. In such situations, the firm becomes a horizontal MNC since firm-level scale economies (eg ownership of a patent) make it advantageous to have the two factories under a common ownership.

In simple versions of these models, firms either engage in trade, or in FDI, but not both. Furthermore, if firms within each sector are similar and countries have similar trade and investment barriers (sector-by-sector), simple versions of these models predict that international commerce in each sector should be dominated either by intraindustry trade or by FDI. As a consequence, tariff-jumping FDI models are not well suited to explain the close correlation between the observed patterns of trade and investment. Two caveats to this statement are pertinent. These single-good/multiplant MNCs do conduct intrafirm trade in intangible 'headquarter services' and/or intellectual property rights. Thus tariff-jumping FDI does encourage trade in invisible, but this does not explain FDI's correlation with visible trade. Second, one might be able to enrich these models in ways that restore a correlation between intermediate-goods trade and investment. Nevertheless, the basic model makes trade and FDI substitutes because the key choice is to supply a market either through exports or through local production.

This paper posits a very different model in which two-way FDI arises due to imperfect competition and in which intraindustry trade and intraindustry investment go hand in hand. The model is designed with an archetypical European consumer-goods multinational (eg Nestle) in mind. Before turning to the model's logic, we paint a picture of the type of trade and investment we are trying to capture with our model.

In certain sectors, the European trade and investment pattern line up very closely for a simple reason. Multinationals like Nestle, or Procter \& Gamble, produce a vast range of consumer goods. While not all varieties are sold in every European nation, the range available in each nation far exceeds the range of varieties produced locally. The point is that each product is typically supplied to many European nations from a single European factory. The locations of these factories are not always - or even mainly - in the 
multinational's home country. Nestle, for example, produces Buitoni-brand frozen pizzas in France, Buitoni-brand fresh pasta in Italy, and it sells both products in both markets. Moreover it "re-imports" both products to Switzerland. In such industries, trade and investment patterns are intrinsically similar, in terms of aggregate bilateral flows as well as in terms of their intraindustry nature and their sectoral composition.

Imperfect competition is at the heart of our explanation of this sort of cross-hauling FDI, just as imperfect competition is at the heart of Brander (1981) and Brander and Krugman (1983) reciprocal-dumping trade. To fix ideas, recall the driving force behind BranderKrugman reciprocal dumping. Profit maximizing firms operate at the point where perceived marginal revenue equals marginal cost. With imperfect competition, perceived marginal revenue has two components - the price (the direct gain from an extra sale) and the revenue-depressing effect (the level of sales times the price-lowering impact of an extra sale). In markets where the firm has few sales, the revenue-depressing effect is negligible, so firms find it optimal to accept a lower price-marginal cost markup. Applying this to a trading world with segmented markets, firms accept a lower producer price on their exports since export sales entail a diminished revenue-depressing effect. How can this explain FDI?

Multinationals in our model are multiproduct firms. The decision of how many varieties to produce faces a similar trade-off between a direct effect (operating profit of the new variety) and a revenue-depressing effect. In the jargon of multiproduct firms, this revenuedepressing effect is called the 'cannibalization' effect because of the way that each new variety eats into the sales of the firm's existing varieties. By analogy, firms are willing to accept a lower rate of return on new varieties produced abroad, if producing the variety abroad reduces the cannibalization effect. Specifically, firms find it optimal to produce some of their varieties abroad since trade barriers partially shield home-produced varieties from the cannibalization effect of foreign-produced varieties, and vice versa. Yet since these are differentiated products, placing a factory abroad has a trade enhancing effect (in the form of re-imports) in addition to the usual trade displacing effect (displacement of exports with local sales of foreign affiliates). As such, trade and investment are not substitutes.

This preliminary draft has three sections after the introduction. Section 2 presents the model and the equilibrium conditions. Section 3 analytically interprets the equilibrium by 
studying a series of special cases. Since the general model is analytically intractable, Section 4 presents some numerical simulation results that illustrate the impact of trade and investment barriers on trade and FDI. The final section contains a summary and our concluding remarks.

\section{The Basic Model}

Consider a world with two identical countries (home ' $h$ ' and foreign ' $f$ ') each with a single factor of production (labour L) and a single differentiated-goods sector (manufacturing $\mathrm{X}$ ). Manufacturing technology is described by the standard linear cost function with $w a_{x} x_{i}$ as the variable costs and $w F$ as the fixed cost, where $w$ is the wage, $a_{x}$ is the unit input coefficient, $x_{i}$ is output of variety $i$. The fixed cost represents the cost of developing a number variety and the cost of building a factory to make it. Taking $\mathrm{L}$ as numeraire and $\mathrm{a}_{\mathrm{x}}=\mathrm{l}$ by choice of units yields $\mathrm{F}+\mathrm{x}_{\mathrm{i}}$ as the per-variety cost function.

The model differs from the standard Dixit and Stiglitz (1977) monopolistic set up since we assume firm-level economies of scope, as in Horstmann and Markusen (1987). That is, in addition to the per-variety production costs, each firm must spend $G$ (a mnemonic for general costs) units of labour on overhead costs regardless of the number of varieties produced. G $>0$ naturally leads to multi-product firms, so Dixit-Stiglitz identity between the number of firms and number of varieties is broken.

Goods are traded, however both nations impose identical frictional (i.e. 'iceberg') import barriers such that each unit sold abroad requires $\tau \geq 1$ units to be shipped. Moreover multinational activity is inhibited by cost-raising barriers such that the per-variety fixed costs are $\Gamma$ times $F(\Gamma \geq 1)$ for varieties manufactured abroad.

The representative consumer preferences are $U={ }_{i=0} \int^{N} \mathrm{c}(i)^{1-1 / \sigma} d i$ where $c(i)$ is consumption of variety $\mathrm{i}, \mathrm{N}$ is the number (mass) of varieties available, and $\sigma>1$ is the elasticity of substitution between varieties. Utility optimisation yields standard CES demand functions for each $\mathrm{X}$ varieties.'

Multinational Corporations To focus on essentials, we assume one multiproduct firm per country. "These firms compete along three dimensions - the number of varieties, the

\footnotetext{
An earlier draft allowed an arbitrary number of multinationals. This complicated calculations without providing any compensating insights.
} 
production-location of varieties, and sales of each variety in each market. This competition takes place in two stages. First, each multiproduct firm decides upon the number of varieties to produce in each location. While real-world firms do produce single varieties in more than one factory, and this is an important feature of the standard MNC model, we wish to distinguish our model as clearly as possible from the standard model. We assume, therefore, that the cost of producing a new vareity in two factories is $2 \mathrm{~F}$. Consequently, firms never find it advantageous to construct two factories for a single variety. In the second stage, firms choose the level of sales for each variety in each market. Note that resale of varieties by unrelated parties (sometimes called 'grey market' sales) is assumed to be prohibitively expensive. Price discrimination between home and foreign consumers is therefore possible.

Two main results are demonstrated below. First as long as barriers to FDI are not too high, each firm produces a range of products in both markets - this is cross-hauling of FDI. Second, all varieties are sold in both markets, so the trade and FDI patterns are intrinsically similar. Showing these results, however, is complicated by the fact that a firm makes two types of sales from each of its two types of factories. The home firm, for instance, sells its locally-made varieties in the home and foreign markets. These are local and traditional export sales. From its foreign-located factories (if any), the home firm sells to the foreign market (these are foreign-affiliate sales) and to its home market (these are re-imports). Importantly, firms are not atomistic so the four optimal levels of sales must be simultaneously determined.

\subsection{Solving the Two-Stage Game}

In the last stage (which is solved first), the number and location of varieties produced by each multinational is pre-determined. The second-stage problem is to find the CournotNash-equilibrium sales for the four types of varieties in the two markets. Even with the four n's as given, the stage-two competition is more complicated than Dixit-Stiglitz monopolistic competition. The reason is that Dixit-Stiglitz firms are atomistic while multiproduct firms are not, so a firm must consider the effects that each variety's sales has on the profitability of its other varieties. Firms' perceived elasticities therefore depend upon market shares, instead of being constant as in Dixit-Stiglitz monopolistic competition.

More specifically, the problem of a typical firm is to maximise operating profit defined 
as $\Pi=n \pi_{h}^{h}+n^{*} \pi_{f}^{h}$, where $\pi_{h}^{h}$ and $\pi_{f}^{h}$ are home-firm operating profit earned on locally produced and nonlocally produced varieties $\left(n^{*}=0\right.$ when there is no FDI). Using a cumbersome but very precise notation in which the superscript indicates owner's nationality, the first subscript indicates production-location, and the second subscript indicates market of sale (eg, $\mathrm{c}_{\mathrm{ht}}^{\mathrm{f}}$ is consumption of a foreign-owned, home-produced varieties sold in the foreign market), $\pi^{\mathrm{h}}{ }_{\mathrm{h}}$ and $\pi_{\mathrm{i}}^{\mathrm{h}}$ are:

$$
\begin{aligned}
& \pi_{h}^{h}=\int_{i \in \Omega_{h h}^{h}}\left[p_{h h}^{h}(i)-1\right] c_{h h}^{h}(i) d i+\int_{i \in \Omega_{h f}^{h}}\left[p_{h f}^{h}(i)-\tau\right] c_{h f}^{h}(i) d i \\
& \pi_{f}^{h}=\int_{j \in \Omega_{f h}^{h}}\left[p_{f h}^{h}(j)-\tau\right] c_{f h}^{h}(j) d j+\int_{j \in \Omega_{f f}^{h}}\left[p_{f f}^{h}(j)-1\right] c_{f f}^{h}(j) d j
\end{aligned}
$$

where the $\Omega^{\mathrm{h}}{ }_{\mathrm{jk}}$ 's are the home firm's ranges of varieties produced in $\mathrm{j}$ and sold in $\mathrm{k}$ (without loss of generality, varieties are ordered such that the $\Omega$ 's are segments on the real line). The four terms in (1) represent the four types of sales made by each firm (local, export, foreignaffiliate, and re-import sales). The four sales levels are chosen independently since markets are segmented, i.e. grey market sales are ruled-out by assumption.

Calculus of Variations The firm's choices - the c(i)'s - are functions, not levels, so calculus of variations is the technique required to solve the optimisation problem. This entails characterizing the optimal functions by studying what must be true about small perturbations of the optimal functions. We start with the home firm's sales to the home market, denoting the optimal functions as ${c^{h}}_{h h}(i)$ and $c^{h^{h}}(i)$; recall that the superscript indicates nationality while the first and second subscripts indicates production-location and market of sale respectively. Consider another pair of functions where only $\mathrm{c}_{h \mathrm{~h}}^{\mathrm{h}}(\mathrm{i})$ is perturbed, specifically $\mathrm{c}^{\mathrm{h}^{\mathrm{h}}}(\mathrm{i})+\mathrm{z} \delta(\mathrm{i})$ and $\mathrm{c}^{\mathrm{h}}{ }_{\mathrm{th}}(\mathrm{i})$, where $\mathrm{z}$ is a scalar and $\delta(\mathrm{i})$ is an arbitrary, continuous function satisfying $\delta(0)=\delta\left(\mathrm{n}_{\mathrm{h}}^{\mathrm{h}}\right)=0$. Using the inverse demand functions, the objective functional can be expressed as a function of $\mathrm{z}$, namely?

$$
\int_{i \in \Omega_{h h}^{h}}\left(\frac{\left[c_{h h}^{h^{\prime}}(i)+z \delta(i)\right]^{1-\frac{1}{\sigma}} E}{\Delta_{h}}-c_{h h}^{h^{\prime}}(i)-z \delta(i)\right) d i+\int_{j \in \Omega_{f h}^{h}}\left(\frac{\left[c_{f h}^{h^{\prime}}(j)\right]^{1-\frac{1}{\sigma}} E}{\Delta_{h}}-\tau c_{f h}^{h^{\prime}}(j)\right) d j+R_{0}
$$

where $\mathrm{E}$ is total consumer expenditure per market and $\mathrm{R}_{\mathrm{o}}$ is a constant reflecting operating profit earned in the foreign market (this is invariant with respect to $\mathrm{z}$ ). ${ }^{3}$ The $\Delta_{\mathrm{h}}$ terms, 
however, do depend on $\mathrm{z}$ according to:

$$
\Delta_{h}(z) \equiv \int_{i \in \Omega_{h h}^{h}}\left(c_{h h}^{h^{\prime}}(i)+z \delta(i)\right)^{1-\frac{1}{\sigma}} d i+\int_{j \in \Omega_{f h}^{h}} c_{f h}^{h^{\prime}}(j)^{1-\frac{1}{\sigma}} d j+\int_{i \notin \Omega_{h h}^{h} \cup \Omega_{f h}^{h}} c(i)^{1-\frac{1}{\sigma}} d i
$$

The optimal function must be such that small perturbations lead to no changes in the objective functional. To characterise the optimal function, we therefore differentiate (2) with respect to $\mathrm{z}$ and set the derivative (evaluated at $\mathrm{z}=0$ ) equal to zero. With Cournot conjectures, the derivative with respect to $\mathrm{z}$ evaluated at $\mathrm{z}=0$ is:

$$
\int_{i \in \Omega_{h h}^{h}}\left(\left(1-\frac{1}{\sigma}\right) \frac{c_{h h}^{h^{\prime}}(i)^{-\frac{1}{\sigma}} E}{\Delta_{h}^{h}(0)}\left[1-\int_{i \in \Omega_{h h}^{h}} \frac{c_{h h}^{h^{\prime}}(i)^{1-\frac{1}{\sigma}}}{\Delta_{h}^{h}(0)} d i-\int_{j \in \Omega_{f h}^{h}} \frac{c_{f h}^{h^{\prime}}(j)^{1-\frac{1}{\sigma}}}{\Delta_{h}^{h}(0)} d j\right]-1\right) \delta(i) d i
$$

Dropping the primes as indicators of optimal functions (we deal only with optimal functions from here on), and using the inverse demand functions, the necessary condition for $\mathrm{c}_{\mathrm{hh}}^{\mathrm{h}}$ to be optimal can be expressed as:

$$
\int_{i \in \Omega_{h h}^{h}}\left(p_{h h}^{h}(i)\left(1-\frac{1}{\sigma}\right)(1-S)-1\right) \delta(i) d i=0
$$

where $S$ is a typical firm's total share in its local market ( $S$ includes home-market sales of both varieties produced at home and re-imported from foreign factories). ${ }^{+}$

Since (5) must hold for all perturbation functions $\delta(i)$, the term in large parentheses must equal zero for all i. Derivation of the pricing rules for the three other types of sales follows an analogous procedure. To summarise, the optimal pricing rules for a typical home firm's four types of sales (local sales, export sales, re-imports and affiliate sales) are:

$$
\begin{gathered}
p_{h h}\left(1-\frac{1}{\epsilon}\right)=1, \quad p_{f h}\left(1-\frac{1}{\epsilon}\right)=\tau ; \quad \frac{1}{\epsilon} \equiv \frac{1}{\sigma}+\left(1-\frac{1}{\sigma}\right) S \\
p_{f f}\left(1-\frac{1}{\epsilon^{*}}\right)=1, \quad p_{h f}\left(1-\frac{1}{\epsilon^{*}}\right)=\tau ; \quad \frac{1}{\epsilon^{*}} \equiv \frac{1}{\sigma}+\left(1-\frac{1}{\sigma}\right) S^{*}
\end{gathered}
$$

where symmetry allows us to drop the nationality superscript, $S$ and $S^{*}$ are the typical 
firm's total market shares in its local and nonlocal markets, and the $\varepsilon$ 's are perceived elasticities. Note that these pricing rules are identical to small-group monopolistic competition with Cournot competition. Expression (6) differs from standard monopolistic competition pricing rules because multiproduct firms are not atomistic. Indeed, as $S$ and $S^{*}$ approach zero, expression (6) approaches Dixit-Stiglitz markup pricing. Using $S+S^{*}=1$, the optimal pricing rules (6) and the demand function, $S$ can be expressed as 5 :

$$
S=\frac{\left(n+\phi n^{*}\right)^{1 / \mathrm{o}}}{\left(n+\phi n^{*}\right)^{1 / \mathrm{o}}+\left(n^{*}+\phi n\right)^{1 / \mathrm{o}}}
$$

where $\phi=\tau^{1-\sigma}$ is a measure of the 'free-ness' of trade $(\phi=0$ in autarky and $\phi=1$ under free trade). Note that without barriers to FDI $(\Gamma=1)$, symmetry implies $\mathrm{S}=\mathrm{S}^{*}$, so the price ratio of imported and local varieties is $\tau$ as in the Dixit-Stiglitz model. When $S>S^{*}$, i.e. when $\mathrm{n}>\mathrm{n}^{*}$, firms price more aggressively in their export markets.

\subsubsection{The First Stage Game: Location}

In the first stage, firms play Nash in the n's. To characterise the equilibrium, we need to express operating profit in terms of the n's. The home firm's total operating profit may be written as $n \pi^{h}{ }_{h}+n^{*} \pi_{h f}^{h}$, where $\pi_{h}^{h}=\pi_{h h}^{h}+\pi_{h f}^{h}$, and $\pi_{f}^{h}=\pi^{h}{ }_{t h}+\pi^{h}{ }_{f f}$. Operating profit is the value of sales time the optimal profit margin, where (as always) the optimal profit margin is the inverse of the perceived elasticity. ${ }^{6}$ Thus using symmetry of markets, $\Pi=E(S / \varepsilon+(1-$ $S) / \varepsilon^{*}$ ), where (7) and (6) give $S$ and the $\varepsilon^{\prime}$ 's as functions of the n's. The Nash first order conditions for the home firm's $n$ and $n^{*}$ are ${ }^{\text {? }}$

$$
\begin{aligned}
& F=\pi_{h}^{h}-n\left[s_{h h} \pi_{h h}(2-\epsilon)+s_{h f} \pi_{h f}\left(2-\epsilon^{*}\right)\right]-n^{*}\left[s_{h f} \pi_{f f}\left(2-\epsilon^{*}\right)+s_{h h} \pi_{f h}(2-\epsilon)\right] \\
& \Gamma F \geq \pi_{f}^{h}-n^{*}\left[s_{f h} \pi_{f h}(2-\epsilon)+s_{f f} \pi_{f f}\left(2-\epsilon^{*}\right)\right]-n\left[s_{f h} \pi_{h h}(2-\epsilon)+s_{f f} \pi_{h f}\left(2-\epsilon^{*}\right)\right]
\end{aligned}
$$

where the second expression holds with equality when there is FDI, namely when $n^{*}>0$.

Intuition Consider the first order condition for $\mathrm{n}$ (top expression). The left-hand side is the marginal cost of introducing a home-produced variety and the right-hand side is the marginal benefit, which itself consists of three components. The first right-hand-side term captures the direct contribution of introducing a new variety. The second and third term reflect the negative 'cannibalization effects', i.e. the fact that raising $\mathrm{n}$ on the margin eats into the sales of all the firm's existing varieties. 
Although writing the first order conditions as in (8) highlights the analogy with the Brander-Krugman first order conditions, (8) can also be expressed as ${ }^{8}$ :

$$
\begin{aligned}
& \frac{S S^{*} E}{\sigma^{2}}\left(\frac{1+2(\sigma-1) S}{n+\phi n^{*}}+\phi \frac{1+2(\sigma-1) S^{*}}{n^{*}+\phi n}\right)=F \\
& \frac{S S^{*} E}{\sigma^{2}}\left(\phi \frac{1+2(\sigma-1) S}{n+\phi n^{*}}+\frac{1+2(\sigma-1) S^{*}}{n^{*}+\phi n}\right) \leq \Gamma F
\end{aligned}
$$

The first-stage equilibrium is described by the $n$ and $n^{*}$ that solves (8) and (9). Nonlinearity rules out analytic solutions for the general case. However, when FDI is unobstructed, $S=S^{*}=1 / 2$ and $n=n^{*}$, so the common solution is $n=(E / 4 F)^{9}$.

\section{Interpreting the Equilibrium: Analytic Results}

To illustrate the causes and consequences of MNCs in our model as well as to highlight the differences between our model and the other models of MNCs, we study the set of trade and investment barriers that permits FDI to arise. We also show that the two-way FDI can be considered reciprocal FDI dumping in a well-defined sense. Finally, we examine the impact of FDI on trade.

\subsection{Existence of FDI Crosshauling}

To examine the existence of FDI in a direct manner, we identify the critical value of investment barriers, call this $\Gamma^{\prime}$, below which two-way FDI occurs. The line of analysis entails finding the $\Gamma$ where both first order conditions (9) hold with equality when $n^{*}=0$ and $n>0$. Taking the ratio of the two necessary conditions, we find ${ }^{10}$ :

$$
\Gamma^{o}=\frac{\left(1+\phi^{2}\right)\left(1+\phi^{1 / \sigma}\right)+2(\sigma-1)\left(\phi^{2}+\phi^{1 / \sigma}\right)}{2 \sigma \phi\left(1+\phi^{1 / \sigma}\right)}
$$

Any level of FDI barriers less than $\Gamma^{\circ}$, will result in an interior solution. Thus FDI occurs whenever FDI barriers are sufficiently low, namely $\Gamma<\Gamma^{\circ}$. By inspection, the threshold $\Gamma^{\circ}$ falls as trade gets freer (i.e. $d \phi>0$ ) and $\Gamma^{\circ}=1$ when trade is cost-less (i.e. $\phi=1$ ). Figure 1 , which plots $\Gamma^{\circ}$ as a function of $\phi$ (taking $\sigma=3$ ), shows these features graphically.

The above result, namely that $\Gamma^{\circ}$ at free trade is unity, is useful in understanding why FDI occurs in this model. Introducing a new variety always 'cannibalises' the sales of 
existing varieties. By producing some varieties abroad, firms can use trade barriers to shield their home-produced varieties from the cannibalization effect of varieties made abroad. Clearly, this only works when trade in goods is restricted, so when trade is almost free, almost any barrier to FDI will make intraindustry FDI unprofitable. Notice, however, that even natural trade barriers such as transport costs and language are sufficient for creating FDI.

Another interpretation of this is that FDI is one additional means of segmenting the firm's customers, as long as trade costs are non-zero. Since segmenting consumers is good for profits, firms undertake FDI as long as it is not too expensive.

\subsection{Reciprocal FDI Dumping}

The FDI that occurs in our model may be considered reciprocal FDI dumping in the sense that firms accept a lower rate of return on their fixed investments abroad. Indeed the motive is very analogous to the Brander-Krugman motive for trade. To fix ideas, recall the logic of Brander-Krugman trade. Taking $\mathrm{p}$ and $\mathrm{p}^{*}$ as the consumer prices for local and export sales respectively, ' $b$ ' as marginal costs, and $\tau$ as frictional trade barriers (as before), the Brander-Krugman definition of reciprocal dumping is that $\mathrm{p} / \mathrm{b}>\mathrm{p} / \mathrm{b} \tau$. This inequality holds since $\theta>\theta^{*}$ (here $\theta$ 's are the market-specific perceived price elasticities). To show that $\theta>\theta^{*}$ we use three facts: (i) a firm's sales to the segmented markets are determined by the first order conditions $\mathrm{p} / \mathrm{b}=1 /(1-\theta)$ and $\mathrm{p}^{*} / \mathrm{b} \tau=1 /\left(1-\theta^{*}\right)$, (ii) firms with larger market shares perceive the price as more sensitive to extra sales, and (iii) firms have larger market shares in their local markets. Note that imperfect competition - in particular the markups $1 /(1-\theta)$ and $1 /\left(1-\theta^{*}\right)-$ is critical to the existence of this trade. If firms were atomistic, their perceived price elasticities would be $\theta=\theta^{*}=0$, so no trade would occur.

To develop this analogy, it is useful to consider a modified version of the Section 2 model that corresponds roughly to the perfect competition in Brander-Krugman analogy. Specifically, suppose that $G=0$ and, instead of one firm per nation, we allow free entry. In 
this case, Section 2 competition collapses to Dixit-Stiglitz competition with each firm producing only a single variety. If multinationals arise in this model, they can only be of the single-variety-multiplant type. To provide the greatest possible incentive for FDI in the modified model, suppose that prohibitive trade barriers are imposed and that there are some (slight) barriers to FDI, i.e. $\tau=\infty$ and $\Gamma>1$.

In this case, single-variety firms will never become multinationals for a very simple reason. Due to symmetry of varieties and marginal costs, every factory in a typical market would yield an operating profit of $\mathrm{E} / \mathrm{N} \sigma$, where $\mathrm{N}$ is the total number of varieties produced in the typical autarkic nation. Free entry sets $N$ such that $E / N \sigma=F$, where $F$ is the per variety fixed cost for local firms. Due to FDI barriers, the operating profit earned by a foreign-owned plant (equal to $\mathrm{E} / \mathrm{N} \sigma$ by symmetry of varieties), would be insufficient to cover the fixed costs $\Gamma F$. Thus no FDI arises (if $\Gamma=1$, then firms are entirely indifferent to engaging in FDI) when firms are atomistic.

FDI does, however, arise when firms produce a range of varieties (i.e. when they are not atomistic). To illustrate this as sharply as possible, consider the Section 2 model (especially $\mathrm{G}>0$ ), where trade barriers are prohibitive and and FDI is somewhat restricted, i.e. $\tau=\infty$ and $\Gamma>1$. As it turns out, the absence of trade greatly simplifies the second-stage game. In particular, since operating profit earned in a market depends only upon the number of varieties in that market, the first order conditions for the number of plants a typical firm places at home and abroad are ${ }^{11}$.

$$
\pi(1-\zeta)=F, \quad \pi^{*}\left(1-\zeta^{*}\right) \leq \Gamma F ; \quad \zeta \equiv \frac{-\partial \pi / \pi}{\partial n / n}, \quad \zeta^{*} \equiv \frac{-\partial \pi^{*} / \pi^{*}}{\partial n^{*} / n^{*}}
$$

where the $\zeta$ 's are the perceived elasticities of $\pi^{*}$ and $\pi$ with respect to $n^{*}$ and $n^{\dagger}$ The second expression holds with equality when $n *>0 .{ }^{12}$ Notice the similarity to the first order conditions for local and export sales in the Brander-Krugman model. Indeed, the BranderKrugman first order conditions are exactly (11) substituting $\pi$ for $p, \zeta$ for $\theta, \Gamma$ for $\tau$, and $F$ for $b$. If $\zeta$ were a simple function of firms' share of varieties, our demonstration would be completed since, with $\Gamma>1$, foreign firms would produce a narrower range of varieties than

Without trade, there is no ambiguity in by writing $\pi_{\mathrm{h}}{ }^{\mathrm{h}}$ as $\pi$ and $\pi_{\mathrm{f}}{ }^{\mathrm{h}}$ as $\pi^{*}$, so we adopt this notation. 
local firms. Unfortunately, the links between $\zeta$, market shares and $\Gamma$ are somewhat involved. The first step is to show that since $\Gamma>1$, firms have larger market shares in their home market than they do in the foreign market.

Direct calculation using the definition of $\pi$ reveals that ${ }^{13}$ :

$$
\zeta=S(2-\epsilon) ; \quad \epsilon=\frac{\sigma}{1+(\sigma-1) S}, \quad S=\frac{n^{1 / \sigma}}{n^{1 / o}+n^{* 1 / \sigma}}
$$

and isomorphic expressions hold for $\zeta^{*}, \varepsilon^{*}$ and $S^{*}$. Even without trade, we still cannot solve analytically for $n$ and $n^{*}$. It is, however, revealing to reformulate (11) in terms of $S$ and $S^{*}$ by multiplying through by $n$ and using the definition of $\varepsilon$. This is useful since $S$ is a monotonically increasing function of $n$, so we can define the implicit function ' $\eta$ ' that maps a firm's total market share into the number of varieties it produces in that market; specifically, $n=\eta[S]$ and $n^{*}=\eta\left[S^{*}\right]$. Using (12) and the implicit function $\eta$, we can write (11) as:

$$
\begin{gathered}
S\left(\frac{1}{\sigma}+\left(1-\frac{1}{\sigma}\right) S\right)\left(1-S\left(2-\frac{\sigma}{1+(\sigma-1) S}\right)\right) E=\eta[S] F \\
S^{*}\left(\frac{1}{\sigma}+\left(1-\frac{1}{\sigma}\right) S^{*}\right)\left(1-S^{*}\left(2-\frac{\sigma}{1+(\sigma-1) S^{*}}\right)\right) E=\eta\left[S^{*}\right] \Gamma F
\end{gathered}
$$

The reformulation allows us to solve the first order conditions for $\mathrm{S}$ and $\mathrm{S}^{*}-$ and thus implicitly for $n$ and $n^{*}$. Note that the left-hand side of (13), we refer to this as MR, is the marginal profit from raising $S$ via the introduction of a new variety. MR is not monotonically decreasing in $S$, however, the second order conditions tell us that it must be falling at the optimum. ${ }^{+}$

Figure 2 plots the left-hand side (MR) and right-hand side of (13) against total market share. The left-hand sides of the two first order conditions - the two MRs - are identical functions of total market share (although they are evaluated at different points). The righthand sides, however, differ as shown in the figure. Both right-hand sides are plotted as upward sloping curves since $\mathrm{n}$ is implicitly an increasing function of total market share. The curve from the first order condition for $n^{*}$ is higher since $\Gamma>1$. The figure shows that

${ }^{\star}$ More precisely, the right-hand side must be increasing in $\mathrm{S}$ faster than the left-hand side. 
in equilibrium $\mathrm{S} \geq \mathrm{S}^{*}$ always, with the strict inequality holding when $\Gamma>1$. This

demonstrates that firms have larger market shares in their home market than they do in the foreign market.

Finally we turn to showing that firms in this case are 'dumping' FDI. Using $\mathrm{S}>\mathrm{S}$ * in (12), we see that $\zeta>\zeta^{*}$, so, from (11), $\pi / \mathrm{F}>\pi * / \mathrm{F} \Gamma$. In words, this says that firms

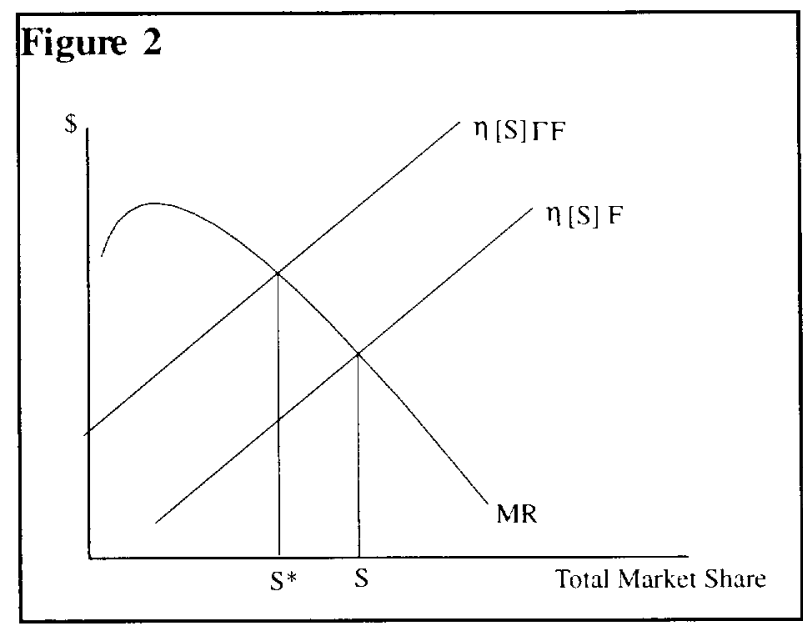
accept a lower average rate of return on their investments abroad than on those at home (due to the reduced cannibalisation effect). This shows that the logic behind reciprocal FDI dumping and the logic behind reciprocal export dumping are identical.

\subsection{Similarity of the FDI and Trade Pattems}

Trade and FDI are not perfect substitutes in our model, however trade and investment do affect each other. The interaction can be illustrated with the following thought experiment, which starts from an initial situation in which firms engage in no FDI. Consider the impact on trade when a home firm moves one single-variety factory from home to foreign. Since each variety has measure zero, the firm's total market shares in home and foreign - namely $\mathrm{S}$ and $\mathrm{S}^{*}$ - are unaffected, so we get no indirect effects on sales via market share changes. The investment, however, has two direct effects on trade. The shifted variety is now supplied to the foreign market via "affiliate sales" rather than exports. This is the trade displacing aspect of investment. However, the variety is now supplied to the home market via "re-imports". This is the trade enhancing aspect of investment. Which effect is larger?

The answer depends crucially on prices. Prior to the FDI, the good was sold in the foreign market at a price of $\tau /\left(1-1 / \varepsilon^{*}\right)$. After the FDI, it is sold in the home market for $\tau /(1-1 / \varepsilon)$. Due to trade and investment barriers $S>S^{*}$, so the markup on sales to its local market - viz. $1 /(1-1 / \varepsilon)$ - is higher than the markup on sales to the foreign market - viz. $1 /\left(1-1 / \varepsilon^{*}\right)$. This is true regardless of where goods are produced. As a consequence the reimports will be priced higher than the exports were prior to the FDI. The volume and value of re-imports after the FDI are therefore less than the volume of and value of exports prior 
to the FDI. In short, FDI does displace some trade, but not all trade as in the singlevariety-mulitplant models.

\section{Simulation Results: The Trade and Investment Pattem}

In analytic as well as empirical studies, FDI may be measured in several ways. As a first cut, we look at the degree of multinationality as measured by the fraction of varieties that firm places abroad, namely $n * /(n+n *)$. The natural benchmarks for this measure are zero (no plants abroad) and $1 / 2$. The former occurs when the actual $\Gamma>\Gamma^{\circ}$, and the latter occurs under unobstructed investment, i.e. when $\Gamma=1$.

Due to the model's nonlinearities (stemming from the simultaneity of prices

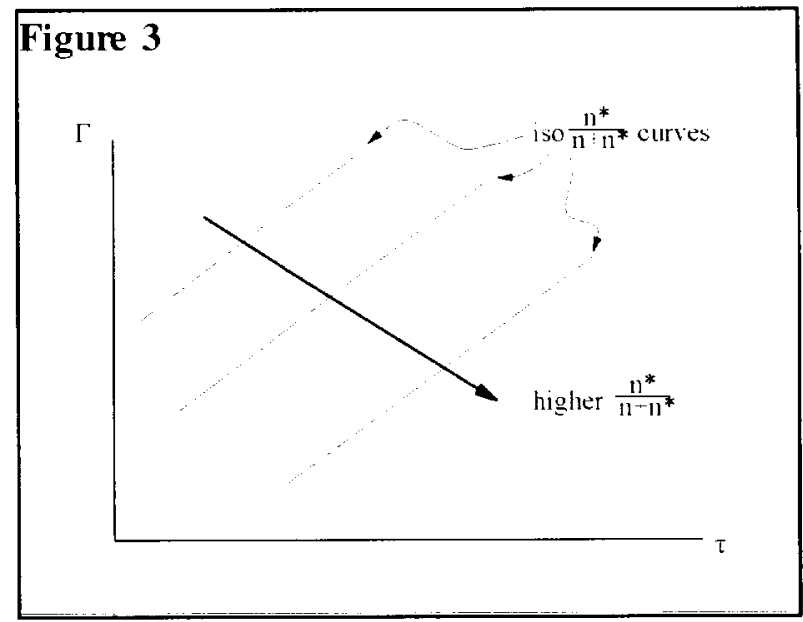
and market shares, and the presence of the non-integer power $\sigma$ ), we cannot get closed-form solutions for $n$ and $n^{*}$, so we must resort to numerical simulation in order to characterise $n^{*} /\left(n+n^{*}\right)$. Figure 3 is a schematic plot of the iso-multinationality contours in $\tau, \Gamma$ space. Thus along each line $n^{*} /\left(n+n^{*}\right)$ is constant; The degree of multinationality rises as one moves to southeast in the diagram.

This figure shows three interesting results. First it implicitly demonstrates that FDI exists for intermediate values of $\Gamma$ and $\tau$ - a result that we could not demonstrate analytically. Second, it reproduces the empirical fact, demonstrated by Brainard (1993b), that as trade barriers rise, individual firms tend to raise their ratio of affiliate sales to exports. Third, it allows us to contemplate the impact that the simultaneous liberalisation of trade and investment would have on multinationality. During the post war period, both trade and investment among rich countries has been substantially liberalised, so we can think of the world as moving in a southwesterly direction. What the figure suggests is that depending upon the rate of relative liberalisation, the degree of multinationality could rise or fall.

\section{Summary and Concluding Remarks}


This paper presents a novel model of foreign direct investment and trade in which intraindustry trade and intraindustry FDI occur simultaneously. The multinationals are multiproduct firms that produce each variety in a single plant. Profit maximizing firms place some of these factories abroad in order the reduce the cannibalization effect that any given variety has on the firm's other varieties. Since firms accept a lower rate of return on the factories they place abroad (rate of return is defined as operating profit of the factory relative to its fixed cost), we think of this as reciprocal FDI dumping.

In this model, FDI has two distinct effects on trade - a trade displacing effect as in the standard single-good/multiple-plant MNC models, and a trade enhancing effect that stems from the export of foreign affiliates back into the home market. As a consequence, intraindustry trade and intraindustry investment go hand-in-hand. 


\section{References}

Blomström, M, R. Lipsey and K. Kulchycky (1988), "US and Swedish direct investment and exports," in Robert Baldwin (ed.) Trade policy issues and empirical analysis, Chicago University Press.

Brainard, L. (1993a), "A simple theory of multinational corporations with a trade-off between proximity and concentration," NBER WP 4269.

Brainard, L. (1993b), "An empirical assessment of the proximity-concentration tradeoff between multinational sales and trade," NBER WP 4583.

Brander, J. (1981) "Intra-industry trade in identical commodities," Journal of International Economics, 11 , pp 1-14.

Brander, J. and P. Krugman (1983) "A 'reciprocal dumping' model of international trade," Journal of International Economics, 15, pp 313-323.

Dixit, A. and Stiglitz, J. (1977), "Monopolistic competition and the optimum product diversity," American Economic Review, 67, pp 297- 308.

Helpman, E. (1984) "A simple model of trade with multinational corporations," Journal of Political Economy, 92, pp 451-471.

Horstmann, I. and J. Markusen (1987) "Strategic investments and the development of multinationals," International Economic Review, 28, pp 109-121.

Horstmann, I. and J. Markusen (1992) "Endogenous market structures in international trade," Journal of International Economics, 32, pp 109-129.

Hummels, D. and R. Stern (1994) "Evolving patterns of North American merchandise trade 
and foreign direct investment, 1960-1990," The World Economy, 17, pp 2-29.

Hymer, S. (1976) The international operation of national firms: A study of direct foreign investment, MIT Press, Cambridge MA.

Markusen, J. (1984) "Multinational multi-plant economics and the gains from trade," Journal of International Economics, 16, pp 205-226.

Markusen, J. (1995) "The boundaries of multinational enterprises and the theory of international trade" Journal of Economic Perspectives, 9, 2, pp 169-189.

Markusen, J. and A. Venables (1995) "The increased importance of multinationals in North American economic relationships: A convergence hypothesis, in Canzoneri, M, W. Ethier and V.Grilli (eds) The new transAtlantic economy, Cambridge University Press.

Markusen, J. and A. Venables (1995) "Multinational firms and the new trade theory," NBER WP 5036.

Motta, M. (1992) "Multinational firms and the tariff-jumping argument," European Economic Review, 36, pp 1557-1571.

Rugman, A. (1985) "Determinants of intra-industry direct foreign investment," in Erdilek, A. (ed) Multinationals as mutual invaders, Croom Helm, Kent, UK.

Smith, M.A.M. (1987) "Strategic investment, multinational corporations and trade policy, European Economic Review, 31, pp 89-96.

Smith, M.A.M. and A. Venables (1988) "Completing the internal market in the European Community: Some industry simulations," European Economic Review, 32, pp 1531-1525. _mnc.wp 


\section{Supplemental Guide to Calculations}

Baldwin and Ottaviano "Multiproduct Multinationals and Reciprocal FDI Dumping"

1. As usual, the direct and inverse demand functions for a typical variety are:

$$
c_{j}=p_{j}^{-\sigma} E / \int_{i=1}^{N} p_{i}^{1-\sigma} d i, \quad p_{j}=c_{j}^{-1 / \sigma} E / \int_{i=1}^{N} c(i)^{1-1 / \sigma} d i
$$

where $\mathrm{E}$ is consumption expenditure and $\mathrm{N}$ is number (measure) of varieties sold in the market.

2. The inverse demand function for a typical variety in a typical market, say home, is:

$$
p_{j}=c_{j}^{-1 / \sigma} E / \int_{i} c(i)^{1-1 / \sigma} d i
$$

where the integral is over all varieties and $\mathrm{E}$ is total market expenditure. With $\mathrm{w}=1$ and $a_{x}=1$, operating profit earned in the home market from a home-produced variety using the perturbed sales function is:

$$
p_{h h}^{h}(i) c_{h h}^{h}(i)-c_{h h}^{h}(i)=\frac{\left[c_{h h}^{h^{\prime}}(i)+z \delta(i)\right]^{1-\frac{1}{\alpha}} E}{\Delta_{h}}-c_{h h}^{h^{\prime}}(i)-z \delta(i)
$$

where $\Delta_{\mathrm{h}}$ as in the text.

Similar substitutions yields the terms under the second integral.

3. E, which is taken as given by firms, equals labour income plus any pure profits earned by firms.

4. More precisely:

$$
S \equiv \int_{i \in \Omega_{h h}^{h}} s_{h h}^{h}(i) d i+\int_{j \in \Omega_{f h}^{h}} s_{f h}^{h}(j) d j ; \quad s_{h h}^{h}(i) \equiv \frac{p_{h h}^{h}(i) c_{h h}^{h}(i)}{E}=\frac{c_{h h}^{h}(i)^{1-\frac{1}{\sigma}}}{\Delta_{h}^{h}}
$$

5. Using the demand function and the cumbersome, but precise notation:

$$
s_{h h}^{h}=\frac{\left(p_{h h}^{h}\right)^{1-\sigma}}{n\left(p_{h h}^{h}\right)^{1-\sigma}+n^{*}\left(p_{f h}^{h}\right)^{1-\sigma}+n^{*}\left(p_{h h}^{f}\right)^{1-\sigma}+n\left(p_{f h}^{f}\right)^{1-\sigma}}
$$


Using the optimal pricing rules, $S+S^{*}=1$ and simplifying the resulting expression, we get:

$$
\begin{aligned}
& s_{h h}^{h}=\frac{(1-S)^{\sigma-1}}{\left(n+n^{*} \phi\right)(1-S)^{\sigma-1}+\left(n^{*}+n \phi\right)\left(1-S^{*}\right)^{\sigma-1}} \\
& =\frac{(1-S)^{\sigma-1}}{\left(n+n^{*} \phi\right)(1-S)^{\sigma-1}+\left(n^{*}+n \phi\right) S^{\sigma-1}}=\frac{(1-S)^{\sigma-1}}{P_{h}}
\end{aligned}
$$

where $\phi=\tau^{1-\sigma}$ is a measure of the 'free-ness' of trade $(\phi=0$ in autarky and $\phi=1$ under free trade), and $\mathrm{P}_{\mathrm{h}}$ is the denominatorfor all market shares in the home market. The formulas for the other three types of shares $s^{h}, s^{h}$ and $s_{h f}^{h}$ are:

$$
s_{f h}^{h}=\frac{\phi(1-S)^{\circ-1}}{P_{h}}, \quad s_{h f}^{h}=\frac{\phi\left(1-S^{*}\right)^{\sigma-1}}{P_{f}}, \quad s_{f f}^{h}=\frac{\left(1-S^{*}\right)^{0-1}}{P_{f}}
$$

where $P_{f}$ is the denominatorfor all market shares in foreign (defined in a manner analogous to $P_{h}$ ). By definition $S$ is:

$$
S=n s_{h h}^{h}+n^{*} s_{f h}^{h}=\frac{\left(n+\phi n^{*}\right)(1-S)^{\sigma-1}}{\left(n+n^{*} \phi\right)(1-S)^{\sigma-1}+\left(n^{*}+n \phi\right) S^{0-1}}
$$

It is straightforward to show that the solution in the text satisfies this definition.

6. Note that the definition of operating profit earned on sales to a particular market is: $\pi=(\mathrm{p}-\mathrm{mc}) \mathrm{c}$, where $\mathrm{mc}$ is marginal cost of selling to the market (including the cost of any trade barriers). From the optimal pricing equation $p(1-1 / \varepsilon)=m c$, so $(p-m c)=p / \varepsilon$. Thus $\pi=\mathrm{pc} / \varepsilon$ as asserted in the text.

7. The first order condition is that $F=\partial \Pi / \partial n$. The hard part is to simplify the partial. The definition of operating profit is:

$$
\Pi=n \pi_{h}^{h}+n^{*} \pi_{f}^{h} ; \quad \pi_{h}^{h} \equiv \pi_{h h}^{h}+\pi_{h f}^{h}, \quad \pi_{f}^{h} \equiv \pi_{f f}^{h} \pi_{f h}^{h}
$$

so, dropping the nationality superscript for convenience:

$$
\frac{\partial \Pi}{\partial n}=\left(\pi_{h h}+\pi_{h f}\right)+n\left(\frac{\partial \pi_{h h}}{\partial n}+\frac{\partial \pi_{h f}}{\partial n}\right)+n *\left(\frac{\partial \pi_{f f}}{\partial n}+\frac{\partial \pi_{f h}}{\partial n}\right)
$$

Start by calculating the partial of $\pi_{\mathrm{hh}}=\mathrm{s}_{\mathrm{hh}} \mathrm{E} / \varepsilon$.

$$
\frac{\partial \pi_{h h}}{\partial n}=\frac{E}{\epsilon} \frac{\partial s_{h h}}{\partial n}+s_{h h} E \frac{\partial(1 / \epsilon)}{\partial n}
$$

The first term involves the partial of $s_{\text {hh }}$. Using the demand function, this can be written as: 


$$
s_{h h}=\frac{c_{h h}^{1-\frac{1}{\sigma}}}{\Delta_{h}}=\frac{c_{h h}^{1-\frac{1}{\sigma}}}{n c_{h h}^{1-\frac{1}{\mathrm{o}}}+n^{*} c_{f h}^{1-\frac{1}{\mathrm{o}}}+Q}
$$

were $\mathrm{Q}$ is the output of the other firm in the home market. Since $c_{\mathrm{hh}}$ is given in the second-stage game:

$$
\frac{\partial s_{h h}}{\partial n}=\left(\frac{c_{h h}^{1-\frac{1}{\sigma}}}{\Delta_{h}}\right)\left(\frac{-c_{h h}^{1-\frac{1}{\sigma}}}{\Delta_{h}}\right)=-s_{h h}^{2}
$$

We frequently encounter the partial of $s_{i j}(i, j=h, f)$ with respect to $n$ and $n *$, so before proceeding, we assert FACT 1:

$$
\frac{\partial s_{i j}}{\partial n}=-s_{i j} s_{h j}, \quad \frac{\partial s_{i j}}{\partial n^{*}}=-s_{i j} s_{f j}
$$

Proof is by repeated application of the manipulation demonstrated above for the partial of $\mathrm{s}_{\mathrm{hh}}$ with respect to $\mathrm{n}$.

The second term involves the partial of $1 / \varepsilon$, where

$$
\frac{1}{\epsilon}=\frac{1}{\sigma}+\left(1-\frac{1}{\sigma}\right) S ; \quad S=n s_{h h}+n^{*} s_{f h}
$$

so

$$
\frac{\partial 1 / \epsilon}{\partial n}=\left(1-\frac{1}{\sigma}\right)\left(s_{h h}+n \frac{\partial s_{h h}}{\partial n}+n * \frac{\partial s_{f h}}{\partial n}\right)=s_{h h}\left(1-\frac{1}{\sigma}\right)(1-S)=s_{h h}\left(1-\frac{1}{\epsilon}\right)
$$

We frequently encounter the partial of $1 / \varepsilon$ and $1 / \varepsilon^{*}$ with respect to $n$ and $n^{*}$, so before proceeding we assert: FACT 2:

$$
\frac{\partial 1 / \epsilon_{i}}{\partial n_{j}}=s_{j i}\left(1-\frac{1}{\epsilon_{i}}\right)
$$

where $\varepsilon_{\mathrm{h}}=\varepsilon$ and $\varepsilon_{\mathrm{r}}=\varepsilon^{*}$.

Putting the elements together:

$$
\frac{\partial \pi_{h h}}{\partial n}=-s_{h h}^{2} \frac{E}{\epsilon}+s_{h h}^{2} E\left(1-\frac{1}{\epsilon}\right)=s_{h h}\left(\frac{-E s_{h h}}{\epsilon}+s_{h h} E\left(1-\frac{1}{\epsilon}\right)\right)=s_{h h}(\epsilon-2) \pi_{h h}
$$

Likewise, using Facts 1 and 2 repeatedly, 


$$
\begin{gathered}
\frac{\partial \pi_{h f}}{\partial n}=s_{h f}\left(\epsilon^{*}-2\right) \pi_{h f} \\
\frac{\partial \pi_{f h}}{\partial n}=s_{h h}(\epsilon-2) \pi_{f h}, \quad \frac{\partial \pi_{f f}}{\partial n}=s_{h f}\left(\epsilon^{*}-2\right) \pi_{f f}
\end{gathered}
$$

Combining these results yields the expression for $\partial \Pi / \partial n$ in the text. A similar procedure yields the expression for $\partial \Pi / \partial n^{*}$.

8. As it turns out, it is easier to re-derive the first order equations using a more direct definition of operating profit.

The value of total sales in the home market is $S$ times $E$ and the operating profit margin on these sales is $1 / \varepsilon$. In the foreign market total sales are $S^{*}$ times $E$ and the operating profit margin on these sales is $1 / \varepsilon^{*}$. Plugging in the expressions for the $\varepsilon^{\prime} \mathrm{s}$ in terms of $\sigma$ and the S's yields the value of profits, i.e.:

$$
\frac{E}{\sigma}\left[S(1+(\sigma-1) S)+S^{*}\left(1+(\sigma-1) S^{*}\right)\right]-\left(n+\Gamma n^{*}\right) F
$$

Taking partials, the first order condition with respect to $n$ is:

$$
\frac{E}{\sigma}\left([1+2(\sigma-1) S] \frac{\partial S}{\partial n}+\left[1+2(\sigma-1) S^{*}\right] \frac{\partial S^{*}}{\partial n}\right)=F
$$

The expression for the partial of $\mathrm{S}$ (using the explicit notation initially to avoid confusion) is:

$$
\frac{\partial S_{h}^{h}}{\partial n_{h}^{h}}=\frac{1}{\sigma} \frac{\left(n_{h}^{h}+\phi n_{f}^{h}\right)^{1 / \sigma-1}\left(n_{h}^{f}+\phi n_{f}^{f}\right)^{\frac{1}{\sigma}}}{\left[\left(n_{h}^{h}+\phi n_{f}^{h}\right)^{\frac{1}{\sigma}}+\left(n_{h}^{f}+\phi n_{f}^{f}\right)^{\frac{1}{\sigma}}\right]^{2}}=\frac{S S^{*}}{\sigma\left(n+\phi n^{*}\right)}
$$

The expression for the partial of $S^{*}$ is:

$$
\frac{\partial S^{*}}{\partial n_{h}^{h}}=\frac{\phi S S^{*}}{\sigma\left(\phi n+n^{*}\right)}
$$

Inserting the partials and simplifying yields the expression in the text for the first order condition with respect to $\mathrm{n}$. The condition for $\mathrm{n} *$ is derived in a similar manner.

9. The general first order condition is:

$$
\begin{aligned}
& F=\frac{\partial \Pi}{\partial n}=\pi_{h}^{h}-n\left[s_{h h} \pi_{h h}(2-\epsilon)+s_{h f} \pi_{h f}\left(2-\epsilon^{*}\right)\right] \\
& \text { - } n^{*}\left[s_{h f} \pi f f\left(2-\epsilon^{*}\right)+s_{h h} \pi_{f h}(2-\epsilon)\right]
\end{aligned}
$$

but with $n=n *$ and $S=S^{*}=1 / 2$, we have: 


$$
\begin{aligned}
& \pi_{h h}=\pi_{f f}=\frac{s E}{\epsilon} ; \quad s=s_{h h}=s_{f f}=\frac{1}{2 n(1+\phi)} \\
& \pi_{h f}=\pi_{f h}=\frac{s^{*} E}{\epsilon} ; \quad s^{*}=s_{h f}=s_{f h}=\frac{\phi}{2 n(1+\phi)}
\end{aligned}
$$

so, reducing the first order condition, we get:

$$
\begin{aligned}
F & =\pi_{h}^{h}-n(2-\epsilon)\left[s \frac{s E}{\epsilon}+s^{*} \frac{s^{*} E}{\epsilon}+s^{*} \frac{s E}{\epsilon}+s \frac{s^{*} E}{\epsilon}\right] \\
& =\pi_{h}^{h}-\frac{n(2-\epsilon) E}{\epsilon}\left(s+s^{*}\right)^{2}=\pi_{h}^{h}-\frac{(2-\epsilon) E}{\epsilon n 2^{2}}
\end{aligned}
$$

Using the expressions for $\varepsilon$ and $\pi_{\mathrm{h}}{ }^{\mathrm{h}}$,

$$
S=S^{*}=\frac{1}{2}, \quad \epsilon=\epsilon^{*}=\frac{\sigma}{1+\frac{\sigma-1}{2}}, \quad \pi_{h}^{h}=\frac{E}{2 n \sigma}\left(1+\frac{\sigma-1}{2}\right)
$$

The first order condition becomes:

$$
F=\frac{E}{4 n \sigma}(\sigma+1)-\frac{E(2-\epsilon)}{4 n \epsilon}
$$

Solving this for $\mathrm{n}$ and rearranging, we get the expression in the text.

10. With $n^{*}=0$, the ratio of the first order conditions is:

$$
\frac{1+2(\sigma-1) S+1+2(\sigma-1) S^{*}}{\phi[1+2(\sigma-1) S]+\frac{1+2(\sigma-1) S^{*}}{\phi}}=1 / \bar{\Gamma}
$$

Since $S+S^{*}=1$, this simplifies to:

$$
\begin{gathered}
\frac{2 \sigma}{\left(\phi[1+2(\sigma-1) S]+\frac{1+2(\sigma-1) S^{*}}{\phi}\right)}=1 / \bar{\Gamma} \\
\frac{2 \sigma \phi}{\phi^{2}[1+2(\sigma-1) S]+1+2(\sigma-1) S^{*}}=1 / \bar{\Gamma}
\end{gathered}
$$

Moreover with $n^{*}=0$, we have:

$$
S=\frac{1}{1+\phi^{1 / \mathrm{o}}}, \quad S^{*}=\frac{\phi^{1 / \mathrm{o}}}{1+\phi^{1 / \mathrm{o}}}
$$

so 


$$
\frac{2 \sigma \phi\left(1+\phi^{1 / \sigma}\right)}{\left(1+\phi^{2}\right)\left(1+\phi^{1 / \sigma}\right)+2(\sigma-1)\left(\phi^{2}+\phi^{1 / \sigma}\right)}=1 / \bar{\Gamma}
$$

Inverting this yields the expression in the text.

11. The definition of operating profit is:

$$
n \pi_{h}^{h}+n^{*} \pi_{f}^{h}
$$

and due to the lack of trade, there is no ambiguity introduced by writing $\pi_{\mathrm{h}}{ }^{\mathrm{h}}$ as $\pi$ and $\pi_{\mathrm{f}}{ }^{\mathrm{h}}$ as $\pi^{*}$, so we adopt this notionation. Note that $\pi$ is not a function of $n^{*}$ and $\pi^{*}$ is not a function of $\mathrm{n}$, so the first order conditions are:

$$
\pi+n \frac{\partial \pi}{\partial n}=F, \quad \pi^{*}+n^{*} \frac{\partial \pi^{*}}{\partial n^{*}}=\Gamma F
$$

Rearranging these, using the elasticity definitions, yields the expressions in the text.

12. The second order condition for $\mathrm{n}$ is:

$$
\frac{\partial \pi}{\partial n}(1-\zeta)-\pi \frac{\partial \zeta}{\partial n}<0
$$

From the first order condition calculations, the partial of $\pi$ with respect to $n$ is $s \pi(\varepsilon-2)$.

Using the definition of $\zeta$, we have:

$$
\frac{-\partial \zeta}{\partial n}=(\epsilon-2) \frac{\partial S}{\partial n}+S \frac{\partial \epsilon}{\partial n} ; \text { where } \frac{\partial \epsilon}{\partial n}=\frac{(-\epsilon)(\sigma-1)}{1+(\sigma-1) S} \frac{\partial S}{\partial n}
$$

since the partial of $S$ with respect to $n$ is $s(1-S) / \sigma$, we have that the second order condition requires:

$$
s \pi\left[(\epsilon-2)(1-\zeta)+\frac{1}{\sigma}(\epsilon-2)(1-S)-S \frac{\epsilon}{\sigma}(\epsilon-1)\right]<0
$$

Direct calculation using (12) shows that this holds for $\mathrm{n}$ (since $\mathrm{S} \geq \mathrm{I} / 2$ with only two multinationals).

The second order condition for $n^{*}$ is isomorphic with $S^{*}, \varepsilon^{*}$ and $\zeta^{*}$ in place of $S, \varepsilon$ and $\zeta$. For general $\sigma$, this need not hold for very small $S^{*}$ (i.e. high barriers to FDI). However, by direct calculation, we can show that it always holds for $S^{*}>0$ when $\sigma \leq 2$. Thus, the analysis in the text applies to cases where $\Gamma$ is not too large, or $\sigma \leq 2$.

13. To demonstrate the expression for $\zeta$, we note that:

$$
\frac{\partial \pi}{\partial n}=\frac{E}{\epsilon} \frac{\partial s}{\partial n}+s E \frac{\partial(1 / \epsilon)}{\partial n}
$$

and as shown in the notes to Section 2 


$$
\frac{\partial s}{\partial n}=-s^{2}, \quad \frac{\partial(1 / \epsilon)}{\partial n}=s\left(1-\frac{1}{\sigma}\right)(1-S)=s\left(1-\frac{1}{\epsilon}\right)
$$

Therefore

$$
\frac{\partial \pi}{\partial n}=s \pi(\epsilon-2) \Leftrightarrow \zeta=S(2-\epsilon)
$$

